\title{
NOTES ON THE MACHINERY EMPLOYED \\ AT THE FORTH BRIDGE WORKS.
}

By Mir. WILliam ARrot, of Glasiow.

The greater part of the Machinery at the Forth Bridge Works is original in design and novel in construction, chiefly because of the unusual nature of the work to be carried out. It may be roughly classified under the following heads :- hydraulic bending and setting, planing, drilling, erecting, and riveting. In designing the machinery and tools to accomplish these different kinds of work, there had ever to be kept in view rapidity of production, with a very high quality of work in the finished structure. An idea of the quantity of machinery provided to deal with the material passing through the shops may be partly formed from the fact that it is eapable of finishing 1,500 tons in a single month.

Hydraulic Bending and Setting Machinery.-To bend and twist the largo steel plates required in the construction of the tubes and their connections, a great variety of hydraulic presses had to be provided. The largest of these, shown in Plate 45, is capable of exerting a pressure of 1,600 tons between the dies. It consists of four 24-inch cylinders $C$, resting on two longitudinal girders $G$ bedded on concrete. From each cylinder rise two iron columns L, which carry a fixed table $F$ overhead. On the top of the rams another table $\mathrm{T}$ is placed, which can be raised or lowered at will. Between these two tables are placed the blocks B which stamp the plates to the desired shape. In most cases this shapo is the arc of a circle, but in others the form is very varying, while in some instances the plates are flanged as well as bent or twisted. In nearly every case, after a plate has been set while heated, it requires 
to be finally adjusted when cooled. To dispense with the heating of the plates gives unsatisfactory work, and is in many cases impossible. In no instance is this plan of bending adopted to any extent without annealing the plates both before and after the work has been put upon them. Much of the final adjusting of the plates is done by presses consisting of a simple ram fixed to the upper of two girders, which are bound together at the ends, the lower girder serving as the seat for the block on which the plate is placed. Numerous other forms of presses are employed for lighter work.

Planing Machinery.-A special class of machinery is employed to plane the elges of the plates. In the case of most of the plates this requires to be done very carefully, because in the structure of the bridge a certain percentage of the stress in compression is taken up by the plates butting, instead of wholly by the rivets as in the tension joints. This statement applies to all plates in the tubes.

The side edges of the curved plates are first of all planed on what may be looked upon as an ordinary planing machine, Plate 46. It is provided however with special double side-cheeks $\mathrm{C}$, between which are two fixed swivelling tool-boxes $T$, one on each side of the machine. These tool-boxes can when desired be transferred to a special cross-slide, as it is sometimes more convenient to work with one box in the cross-slide than with both between the side. cheeks. Both tools act together and cut continuously, that is during the backward as well as the forward travel of the table. The plate to be planed is fixed upon curved blocks $B$, which in turn are securely bolted to the table.

For planing the end edges of the curved plates a special machine had to be designed and built, Plate 47 , in which the plate is secured to a fixed table $\mathrm{B}$, Figs. 6 and 7 , while the tool $\mathrm{T}$ is made to travel backwards and forwards in a swinging pendulum $P$ that receives its motion through a connecting-rod from a travelling saddle $\mathrm{S}$. The tool cuts both ways in this instance also, and is fed to its work by liand.

The planing machines employed to finish the side and end edges of the rectangular plates for girder work, Plates 48 and 49 , are of 
the usual pattern for plate-edge planing, but with the addition of an end slide $\mathrm{E}$ provided with a separate tool, for planing one end edge of the plate $\mathbf{P}$ at the same time that one of its side edges is being similarly treated. This machine finishes a plate at two settings, with the certainty that the ends are at right angles to the sides.

In some machines two saddles are upon the main slide, and in others two tools are in one saddle; both devices have their advantages. The facing of the tees, angles, and other sections, is done as a rule by cold steel saws, in order to secure good butting.

Drilling Machinery.-As will be inferred from the varying character of the work, the drilling is performed by various classes of machines. The principle kept in view is that, wherever possible, girders, tubes, \&c., should be drilled only while their various parts are temporarily built and held togother by bolts in the position they will finally occupy in the finished structure; in this way the highest class of work is obtained.

For drilling the tubes, the machines, each complete in itself, are made large enough to embrace the entire circumference of the tube. As shown in Plates 50 and 51, they consist of a wrought-iron under-frame or carriage $C$, on which are placed the engine and boiler. On it are also fixed two large cast-iron annular rings or headstocks $\mathbf{R}$, embracing the tube $\mathbf{T}$, round which ten drilling slides $\mathrm{S}$ and heads $\mathrm{H}$ travel circumferentially. The slides are moved around the rings and consequently around the tube by a worm at each end, gearing into a worm-wheel that forms part of the rings $R$. The motion of the drill-heads $\mathrm{H}$ on the slides $\mathrm{S}$ is longitudinal, or parallel to the tube. These two motions easily permit of the ten drills working at any part of the circumference of the tube comprised between the two annular rings $R$, which embrace a length of 8 feet. When this length is finished the whole machine is travelled forwards, and is again ready to drill a new length of 8 feet. The tube rests on timber blocks, which are removed from the front and placed behind as the machine travels forwards. In the case of the lighter tubes, the rate of drilling is as high as 12 lineal feet of tube per shift of ten hours; this represents about 800 holes drilled. 
The booms of all girders are drilled separately on blocks, thus leaving the bracings to be drilled to template, which is done by radial drills at another time. The machines employed to drill the booms are of a wholly different kind from those used for the tubes. They are moved along rails, running on each side of the blocks upon which the booms are built, and parallel with them. As shown in Plates 52 and 53, they consist of a double carriage $\mathrm{C}$ with upright columns $\mathrm{L}$, connected together by means of a crossbeam $B$ and sundry other framing for carrying the shafts, pulleys, etc. To the columns and crossbeam are secured slides, to which nine fixed drill-heads $\mathrm{H}$ are bolted on the front of the machine; while to the back are attached four radiating arms $A$, each carrying a single drill. In this way there are both fixed and swinging drills on the two sides of the machine, capable of drilling holes in either a horizontal or a vertical planc. The fixed drills serve for all holes in the regular pitch, while the movable drills take what may be called odd holes, such as those where the struts and ties are to be secured to the booms. All the fixed drills are self-feeding, but the movable ones are fed by hand. The number of drills simultaneously at work varies greatly; at times as many as the full number of thirteen have been employed together on a single boom.

Other machines having radials with only single drills, as shown in Fig. 11, Plate 49, are used for a special class of drilling, and are found to work to great advantage. With the exception of a few special tools, all the remaining drilling is done by radials capable of making a complete circle round the column on which they are supported. Tables are placed on each side of these machines, and the work is fixed on one of the tables; and as the drills are placed at a convenient distance from one another, all the drilling required is easily accomplished without a second shifting of the work.

Erecting and Riveting Machinery.-To erect and rivet such large quantities of material at the immense height at which much of it requires to be done demands a large quantity of special plant for riveting and other purposes. The ordinary class of riveting is accomplished by means of small portable riveters, shown in Figs. 14 
and 15 , Plate 51 , consisting of two arms held apart by links and stays; one arm acts as the holder-up $\mathrm{H}$, while the other carries the hydraulic cylinder $C$ for supplying the power, the cylinder and arm together forming one casting. For some of the more difficult work, where neither could this form of riveter be employed nor could the work be done by hand, small direct-acting hydraulic cylinders were used; the die for forming the rivet-head was here fixed into the piston. Two 4-inch cylinders were usually employed, held to their work either by hard wood packing placed against the permanent structure, or by temporary girders brought into proper position. In these machines the pressure employed was 3 tons per square inch. A large amount of excellent work was performed by these machines in positions where it was practically impossible to do it otherwise.

The riveting of the vertical columns of the piers is done by riveting machines attached to the undersides of the lifting platforms. They are lifted with the platform, and do their work while the platform is at rest. As shown in Plates 54 and 55, they consist of two longitudinal girders or uprights $G$, one on the outside and the other on the inside of the column C. Along the face of each girder a riveting cylinder $R$ is raised or lowered by hydraulic power. The inside girder has a trunnion at top and bottom, fitting into a step in two temporary diaphragms $F$ for supporting the thrust of the rams in riveting. It is turned round on the trunnions at will by means of worm gearing, so tis to rivet up an entire length of 16 feet of the tube circumferentially as well as longitudinally. The outside girder and riveting cylinder when at work always face the inside. The outside girder is attached at top and bottom to two wrought-iron rings $W$, which encircle the column, and not only furnish the necessary support but also permit of the outer riveting cylinder being moved round the column by hydraulic power as required. Over 800 rivets have been closed in a day by one of these machines.

In the erection of the large piers of the bridge, hydraulic power is utilised to a great extent. The principle adopted is to build the piers from off a platform raised by hydraulic pressure as the work of erection proceeds, utilising the piers themselves in process of building as the support of the rising platform. 


\section{Discussion.}

Mr. W. Ford Suith said the whole of the machinery described in the paper certainly appeared to him to be very ingenious and well adapted to the work it had to do, although he had not yet had the pleasure of seeing it in operation.

Mr. Jasies Platt was sure that all engineers who had followed the progress of the work at the Forth bridge must have been struck with the admirable manner in which the author had met all the difficulties in his way. He had shown how by machinery work could be accomplished which had been hitherto thought impossible except by hand. The Members were greatly obliged to him for describing to them the many appliances he had used on this vast structure; and they were looking forwards to a great treat in witnessing the performance of his machines.

Mr. Joseph Barrow had recently had the pleasure of seeing the machinery described in the paper; and had been greatly impressed with its remarkable adaptability for the work it had to do. One point which had especially struck him was no doubt interesting to all engineers, namely the amount of power needed for drilling a large number of holes. Gonerally speaking, the maximum rate of drilling holes in wrought-iron or steel was an inch hole through an inch depth in one minute; but when, as in the present case, from ten to thirteen drills were in operation simultaneously, it was cxceedingly difficult to maintain that rate of work collectively for the whole number. Having however observed the time with his watch, he rather thought that the full amount of work was done by each of the drills. As shown in Plates 50 and 52, the drills were all driven by an endless rope; and it would be interesting if the author could give the velocity of the rope in feet per minute in relation to the number of drills and the work done. In multiple drilling it had always been very difficult to get a number of drills working together, withont a great reduction in the amount of work done by them collectively. It would be seen that the drill used was of a kind having a turned-up 
(Mr. Joseph Barrow.)

lip, such as was used in ship-yards. IIe also wished to refer to the very ingenious withdrawing motion employed in connection with the feed motion, by which any number of the dxills were stopped while the rest were going on. There were also a large number of other practical points of great interest to mechanical engineers, which the Mombers would have the opportunity of examining in their visit to the works.

Mr. Daniel Adamson, Vice-President, said he had originally been led to drilling by the difficulties in dealing with angle-iron or angle-steel ; and he was so well satisfed with its desirability and its excellence when adopted on a small seale that for very many years past he had adopted drilling altogether. He had then made a series of experiments showing that violence of any sort was injurious to a stcel plate, and that punching was deleterious and ought not to be adopted. The most important thing that had impressed him in comnection with the present paper was the riveting appliances. It would be interesting to hoar from the author whether there was any uniformity in the force required for closing rivets of different diametcrs. If for example a given force was required for closing a rivet of one inch diameter, did it require four times the force to close a rivet of two inches diameter, being four timos the area? In his own expcrience ho had not been able to satisfy himself that this was the case. All his riveting was done by steelyards, so that he knew exactly the force that was brought to bear upon the rivet; and he should be thankful to get some rule for the force requisite to close rivets cf different areas. Taking the diameter in eighths of an inch, and represonting by 64 the force required for an inch rivet, was it to bo inferred that for a $\frac{3}{4}$-inch rivet a force of only 36 was all that would be requirad? That was not the result of his own experience, for he had found it required much more to close a $\frac{3}{4}$-inch rivet in proportion to its area than it did to close an inch rivet. In the anthor's lirge experience, with such excellent machinery and such a variety of diamcters of rivcts, he must have obtained a great deal of information that was not in the possession of engineers dealing with a more limited range of riveted work. 
Mr. A. B. Brown believed the author had been the first to devise a complete set of portable tools for the purpose of putting a bridge together; he had previously employed that system for erecting the Broomielaw Bridge in Glasgow. At the Forth bridge almost every tool was exceedingly handy, and answered its purpose remarkably well. The only objection that he had to any of the tools was the general use of leather packings in the hydraulic machines; and his objection to the use of leather packings was that when it was necessary to renew a leather the machine required to be taken to pieces. Otherwise he considered the tools described in the paper were exceedingly good.

Mr. Chardes Cochrane, Vice-President, enquired with reference to the uso of accumulators, whether the work was done by one set of pumps with an accumulator to distribute the water-pressure over the whole of the works, or whether there were several accumulators in different parts of the works; or whether recourse was had to any new appliance for providing hydraulic power, such as a set of triple pumps with fly-wheel, delivering a stream of water which merely circulated as long as the tool was not called into operation; but the moment pressure was wanted and the tap was turned on, the whole momentum of the fly-wheel on the pumps came into play, so that in the riveting machines the head of the rivet was driven home with remarkable efficiency.

Mr. W. Sinver Hall would be glad if the author could give some figures from which to calculate the power required for bending a plate of given thickness to a certain extent. He presumed the plates were all bent at a low red heat, not at a very high temperature.

Mr. T. HonRy Riches, Member of Council, enquired with regard to the column-riveting machine shown in Plates 54 and 55, how the central pillar or holder-up for the riveting machine was adjusted into the proper position, so that the thrust of the rivcter outside the column might exactly coincide with that of the holder-up on the 
(Mr. T. Hurry Riches.)

inside. He rished to know how the two points were adjusted so as to meet the rivet on both sides.

As to the pressure required for closing rivets of different sizes, from his own experience it appeared that not only did the diameter. of the rivet enter into the question, but also the thickness of the plate or plates through which the rivet was being closed. Where thicker plates were used, larger rivets were also generally used, though not nccessarily in all cases. But in every case where thicker plates were used, it became necessary to employ a higher pressure in order to ensure the thorough closing of the plates and rivets, even when the rivets were not larger in diameter than those used for thinner plates.

Mr. C. J. Appleby, having already visited the bridge and seen the machinery there used, was of opinion that similar appliances might certainly be profitably employed in many other undertakings of a very different character. The remarkable ingenuity displayed in the adaptation of the different tools could be realised to sone extent from the drawings illustrating the paper; but would be appreciated still more highly when the works themselves were inspected. From these machines he was quite sure that many valuable ideas would be gathered, which could be used under other circumstances with great advantage to all concerncd.

Mr. Benjamin Walker, Member of Cuuncil, had nothing but praise for the machinery described by the author, which he regarded as remarkable even more for its common-sense character and for its adaptability to the work to be done than for the ingenuity displayed in its design.

Mr. Arrou said the speed at which the ropes were generally run for driving the drilling machines was 1500 or 1600 feet per minute. This high speed was adopted more with a view to the life of the ropes than for getting greater power, because a rope running at a lower speed did not last nearly so long. The ropes running at 1600 feet per minute would last about two years. A great amount of 
power was absorbed by the friction of the pulleys necessary to carry long ropes. The longest ropes he was using were 700 feet in length. On account of the number of different appliances, and the facilities for moving the machines about, it was more advantageous to have a good long rope working over a long stretch.

With regard to riveting, there were various sizes of machines for various sizes of rivets. There was a great deal of difference in riveting steel and iron rivets. Steel rivets required a machine about an inch bigger in diameter than iron rivets of the same size; where a 9-inch ram would suffice for iron rivets, a 10-inch ram was required for steel rivets. The heating of the rivets of course made a great deal of difference also; when a rivet was cold it required a great deal more power to get it in, and it was left unshapely.

The President asked how the rivets were heated.

Mr. Arrol replied they were heated in small furnaces, in which both coal and oil had been tried. Latterly cheap crude oil from the gas works had been adopted, and it had worked successfully. Many riveting furnaces had been rnade, and their size had been reduced to the smallest possible, about 4 feet long by 15 inches high and 12 inches wide. One of these small furnaces could heat rivets for two machines.

For the packings of the hydraulic machines he had not yet found anything better than lenther. Metallic packing had been tried, but it was of no use. The hydraulic machines were worked by a loaded accumulator in the ordinary way. A steam accumulator was also used, but was not worked regularly. Different sets of pumps and accumulators were employed for each part of the works, onc on the south side and one on the north. In sinking the caissons the hydraulic power for working the digger in the chamber at bottom had been limited, as the shops had required it all at that time; and a steam accumulator had becn used, which was a handy tool. $\mathrm{He}_{\mathrm{e}}$ had used two of these, one at the Tay bridge at Dundee, and the other at the Forth bridge. 
(Mr. Arrol.)

The plate bending of course, just like the riveting, required a heating apparatus, and suitable presses having always plenty of power for bending the plates with the least possible trouble.

In regard to the large riveting machine for riveting the vertical columns of the piers, Plate 55, there were ten upright beams $\mathrm{B}$ inside the column $\mathrm{C}$; against five of these the angle frames $\mathrm{F}$ of the machine butted, and transferred the pressure to the outside ring girder W, which had wedges between it and the column $\mathrm{C}$, opposite to the points of bearing within the column. Both the outer and inner frames were strong enough to resist the whole force of the riveting cylinders. As the outer frames $W$ were exactly opposite the inner $F$, the whole thrust from the riveting cylinders went right through from one pair of frames to the other. As soon as the man inside the column had put the red-hot rivet into the hole, he adjusted his riveting cylinder to close it, and at the same time the man outside did exactly the same with the outside riveting cylinder, independently of the inside man. When the outside man was ready, he gave two taps as a signal; then a boy turned on the water, and the two riveters closed up together upon the rivet, the same water supplying both machines simultaneously.

The President enquired whether the difference could be stated between the cost of riveting under the special circumstances here existing, and the cost in ordinary shop work.

Mr. Anrol said there were here so many different kinds of work to be done that it was hardly possiblo to answer that question. In ordinary bridgo work it would make very little difference in cost whether the riveting were done in the shops or on the bridge itself.

The President was sure the Members would be glad to return Mr. Arrol their hearty thanks, both for the excellent paper he had given them, and also for what ho was going to show them in their visit to the works this afternoon. 
FORTH BRIDGE MACHINERY.

Hydraulic Bending Press.

Fig. 1. Transverse Section.

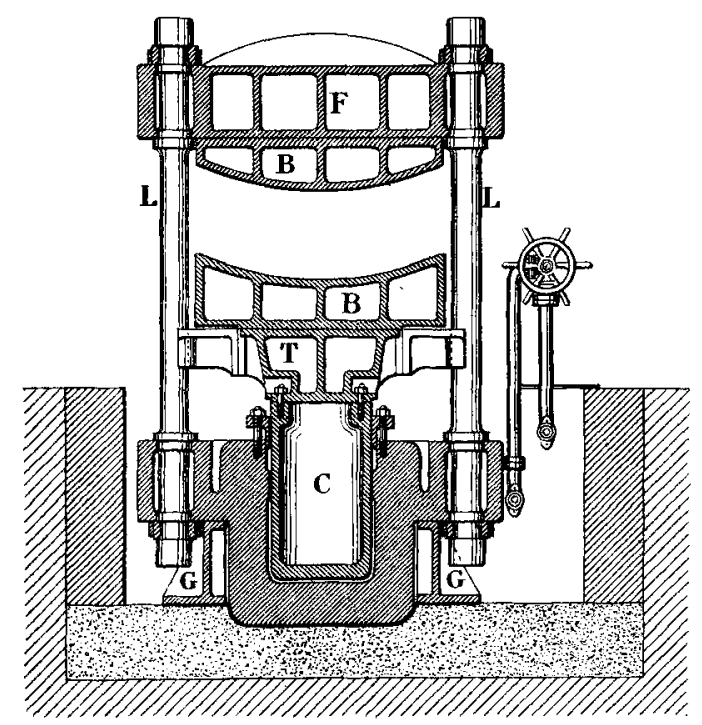

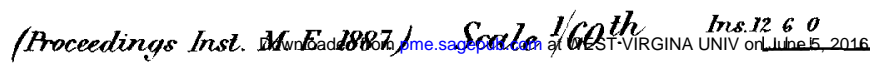

Fig. 2. Half Side Elevetion ! Half Longitudinal Section.

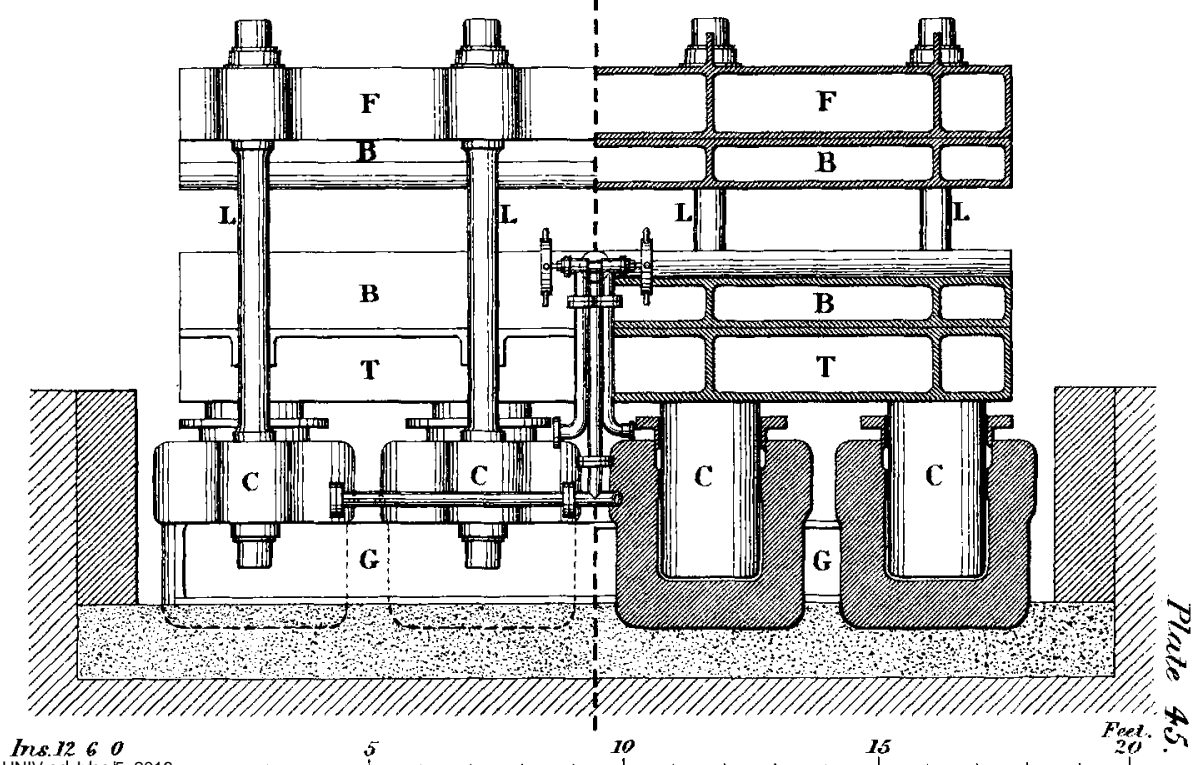




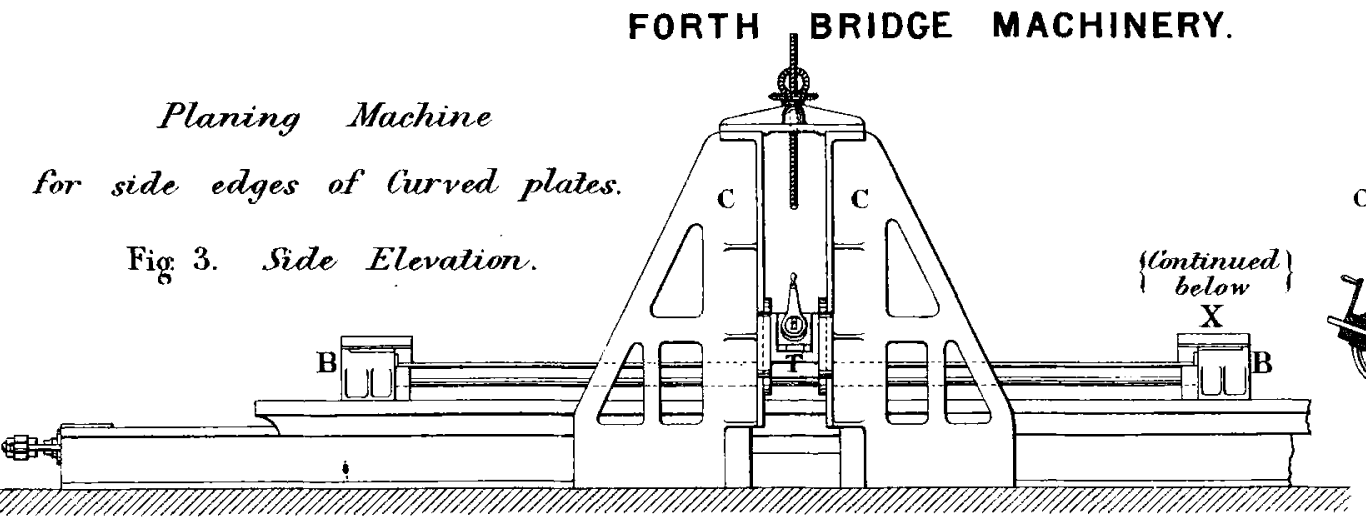

Fig. 3.

(Contimation)

$\{$ from above
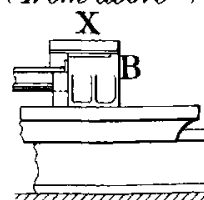

(Proceedings Inst. M. E. 1887) lies. 12 o

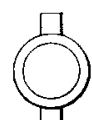

10

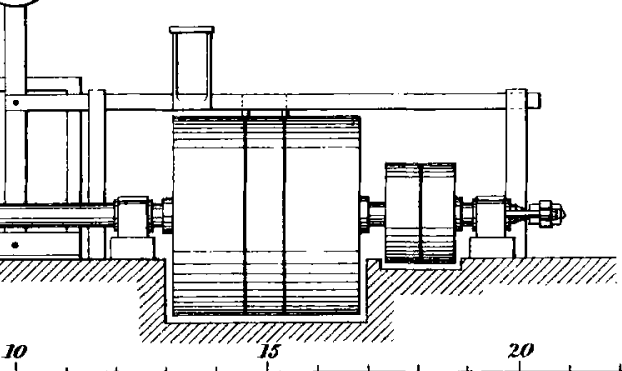

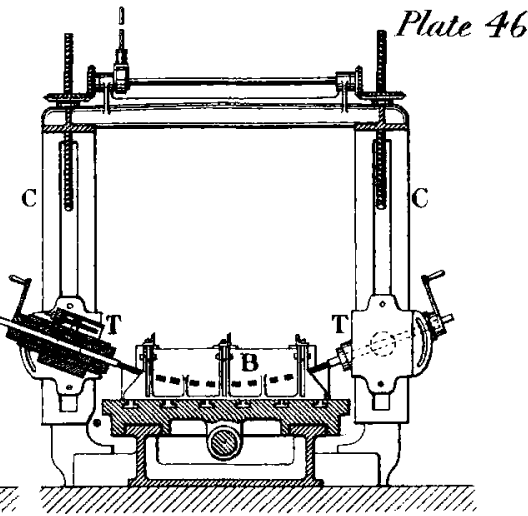

Fig: 4

Transverse Section.
Scale $160^{t h}$ so Feet. 


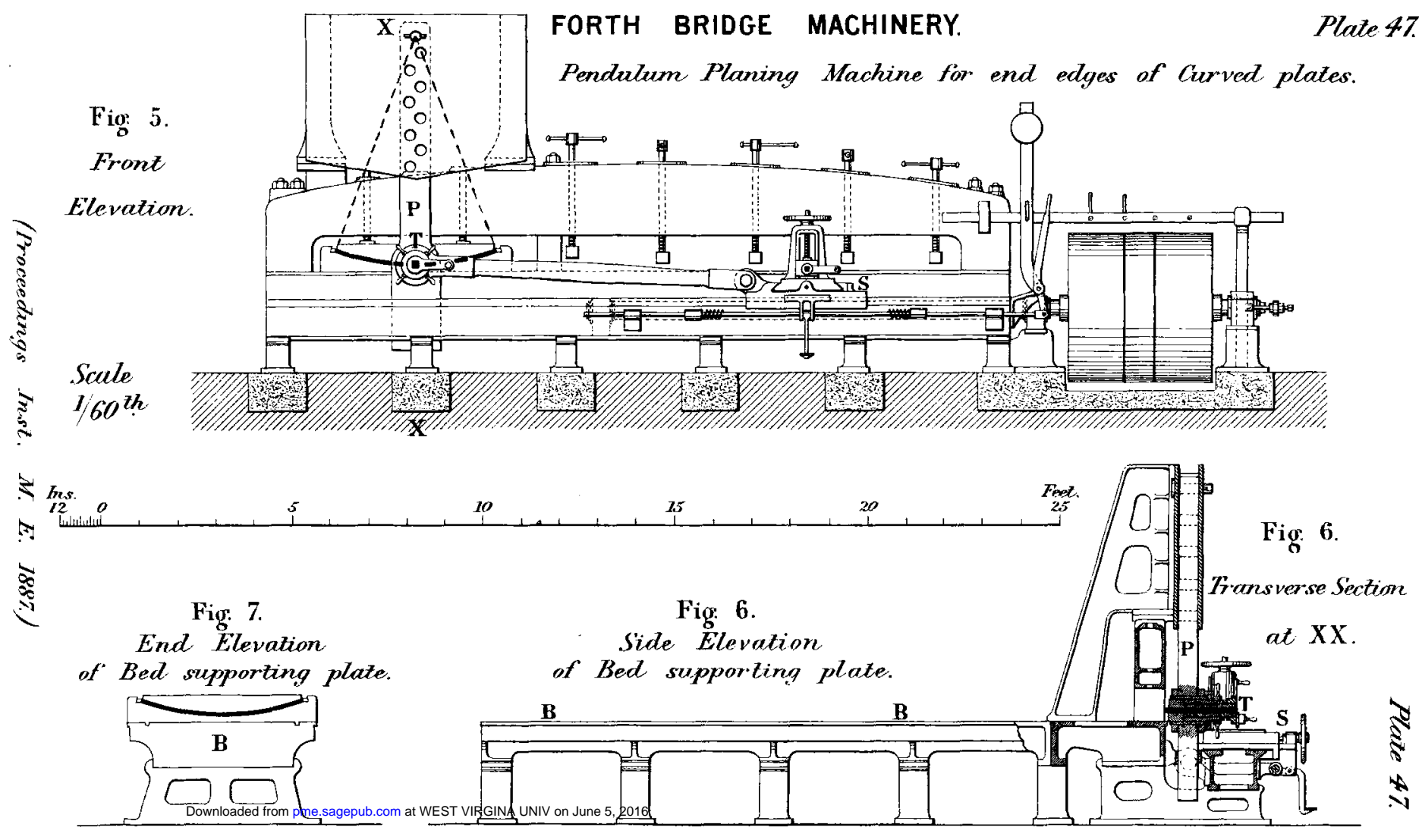




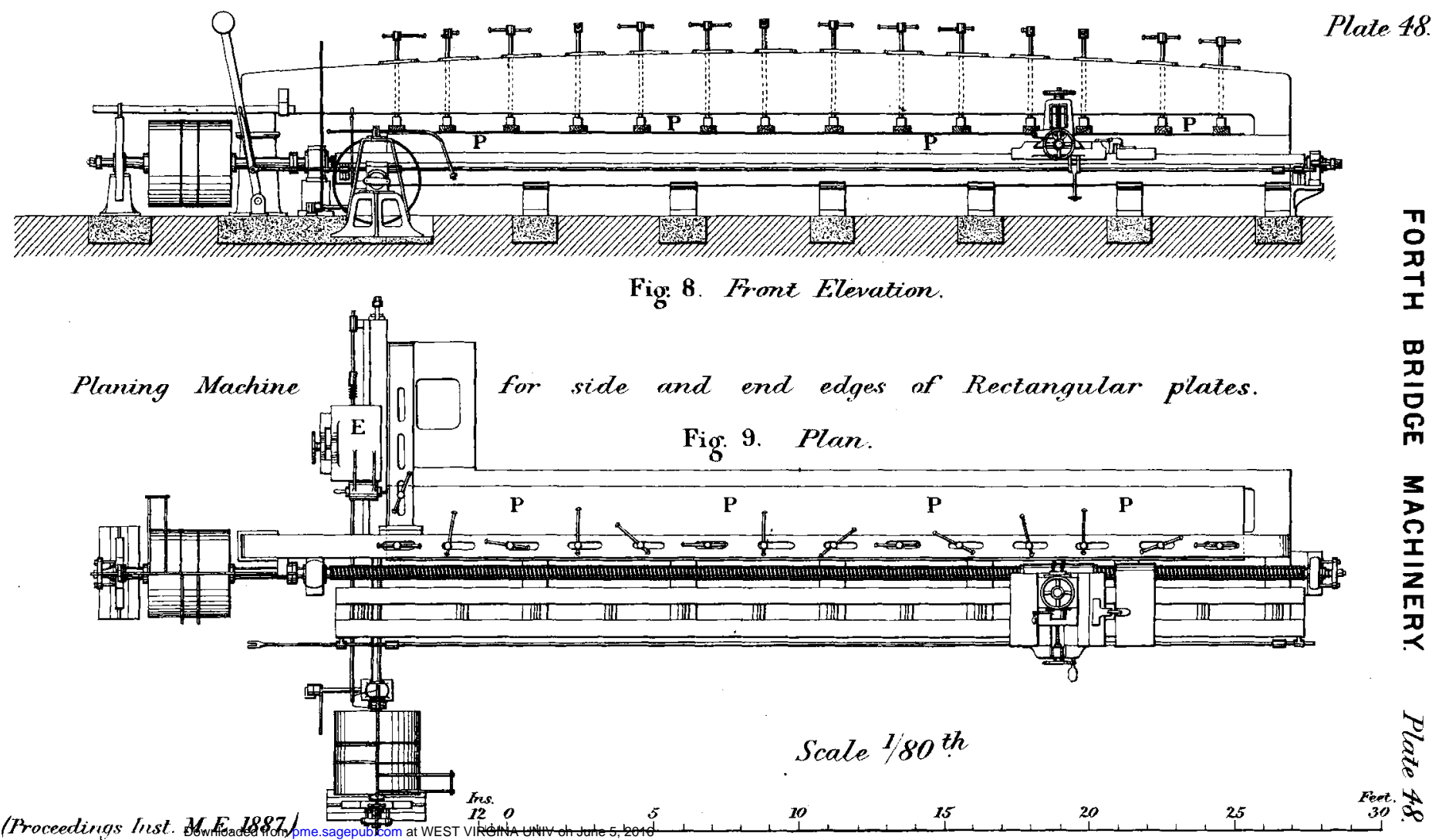




\section{FORTH BRIDGE MACHINERY.}

Planing Machine

for side and end edges

of Rectangular plates.

Fig. 10. End Elevation.

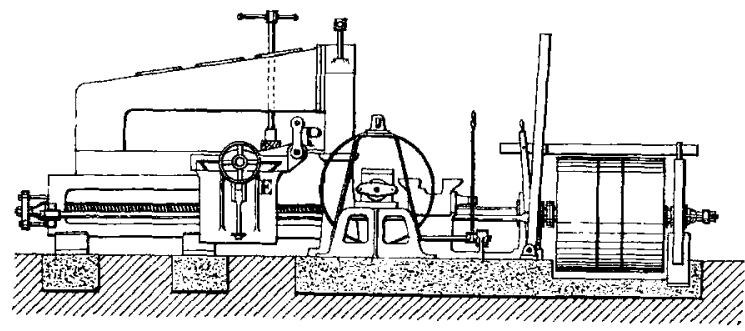

Scale $1 / 80^{\text {th }}$

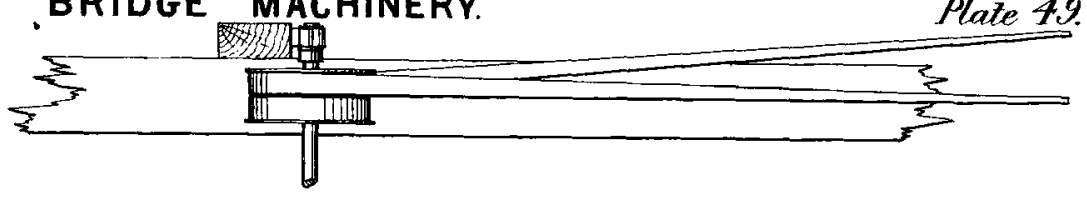

Fig. 11. Radial Drilling Machine.

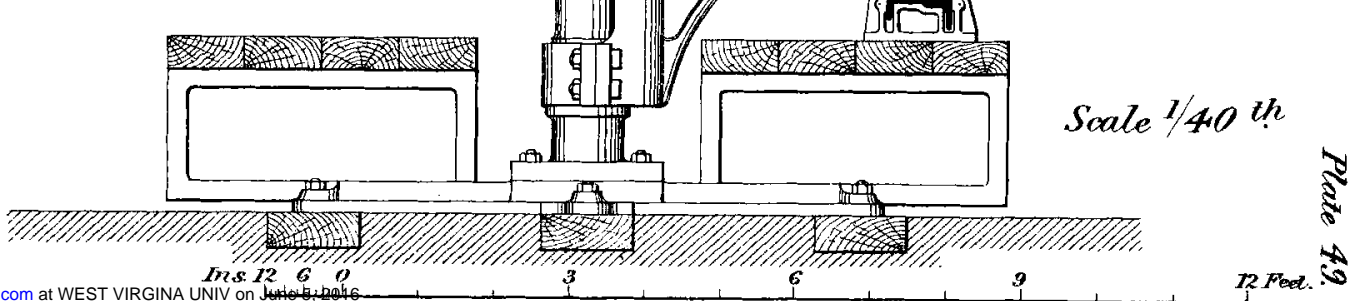




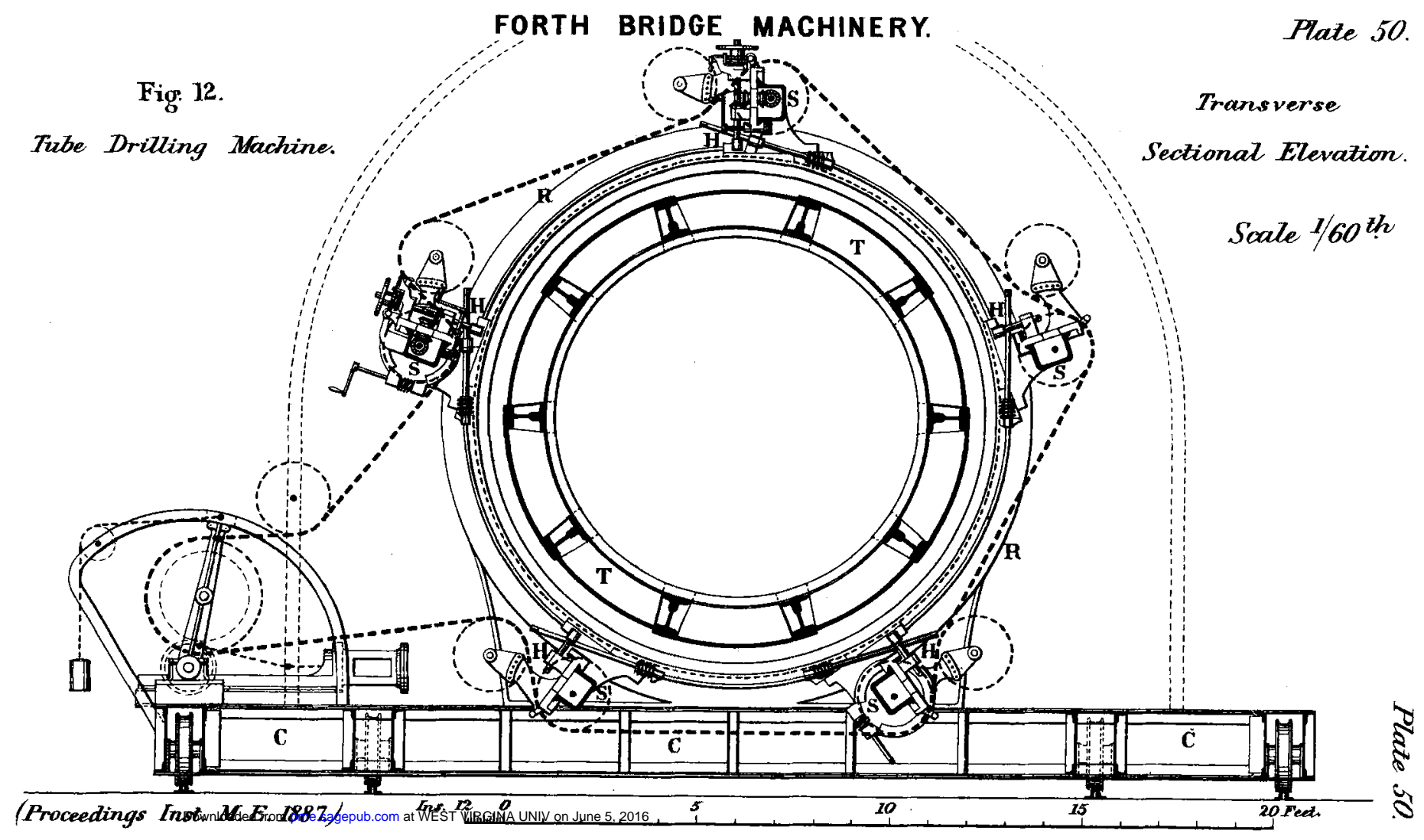




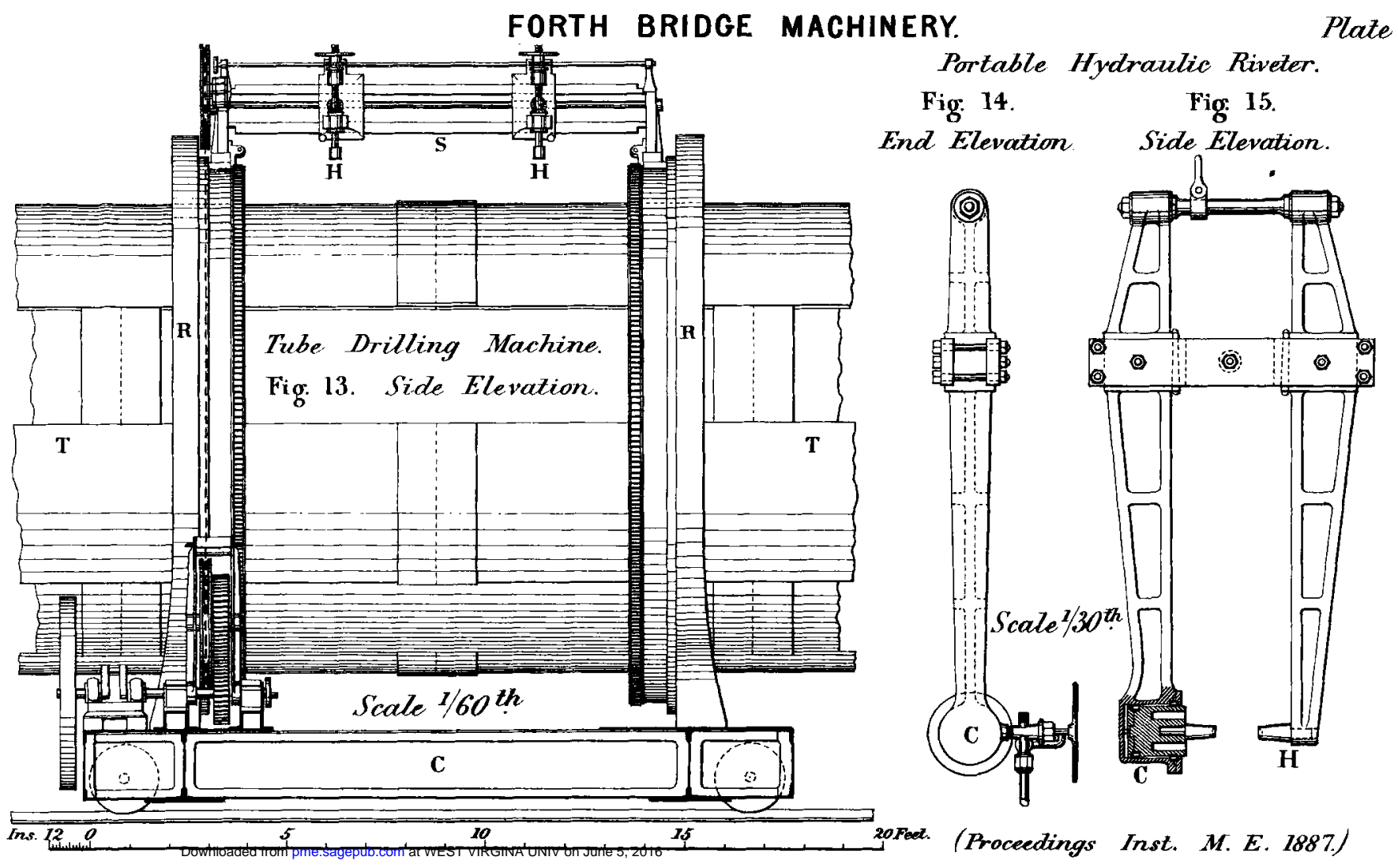


FORTH BRIDGE MACHINERY
Mulliple Drilling Machine.
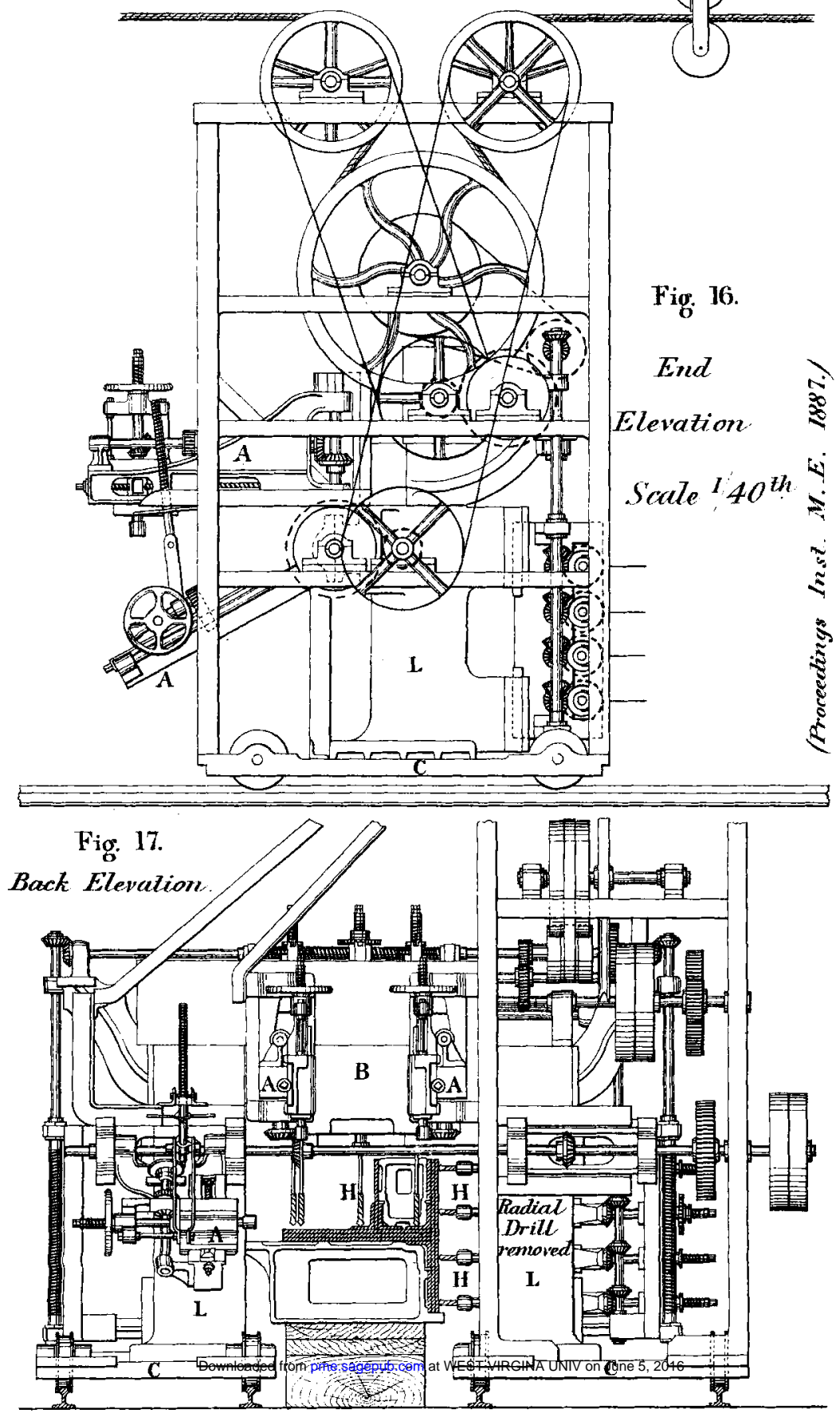
FORTH BRIDGE MACHINERY. Plate53.
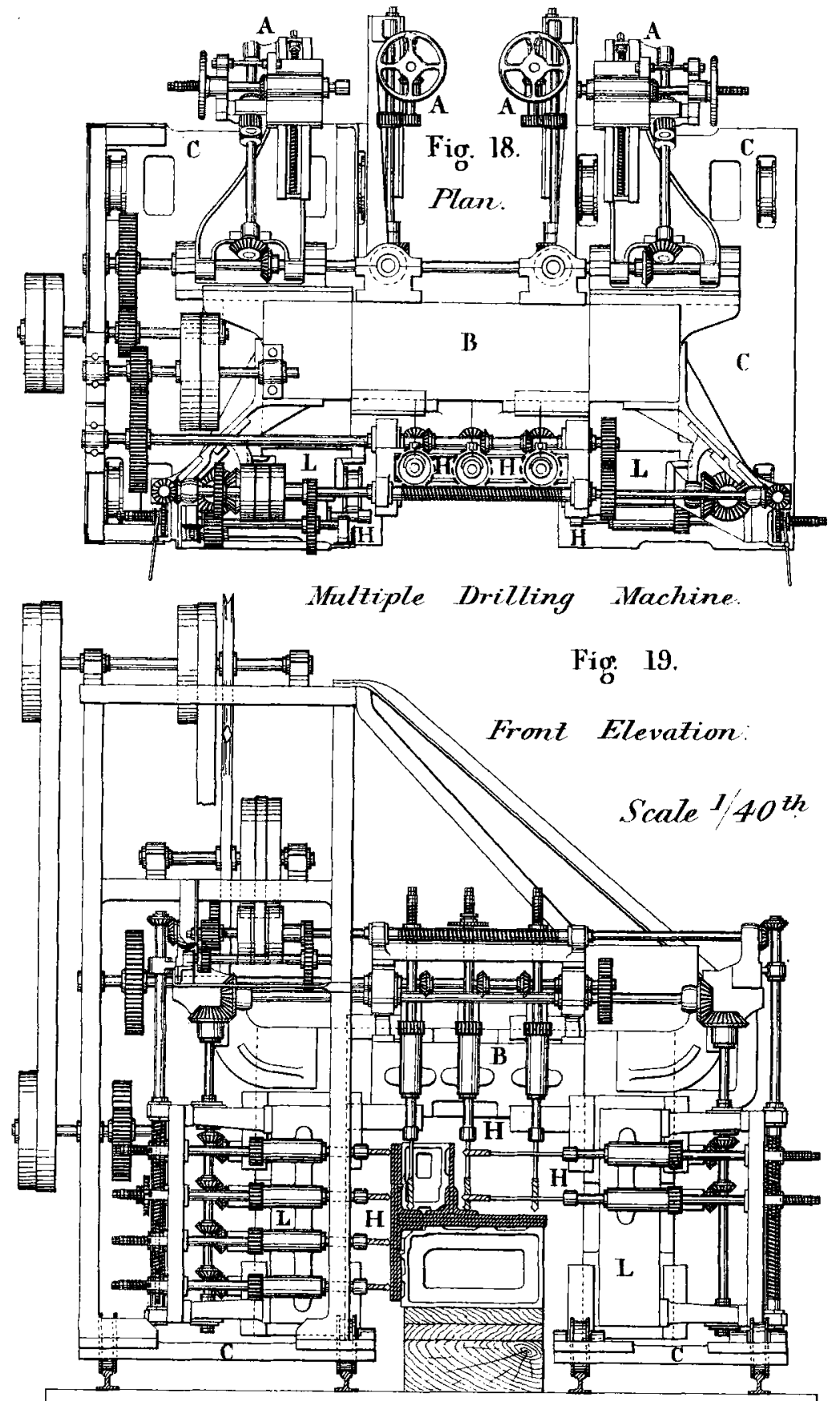
FORTH BRIDGE MACHINERY. Plate 54.

Riveting Machine for Vertical Columns of Piers.

Fig. 20. Vertical Section.

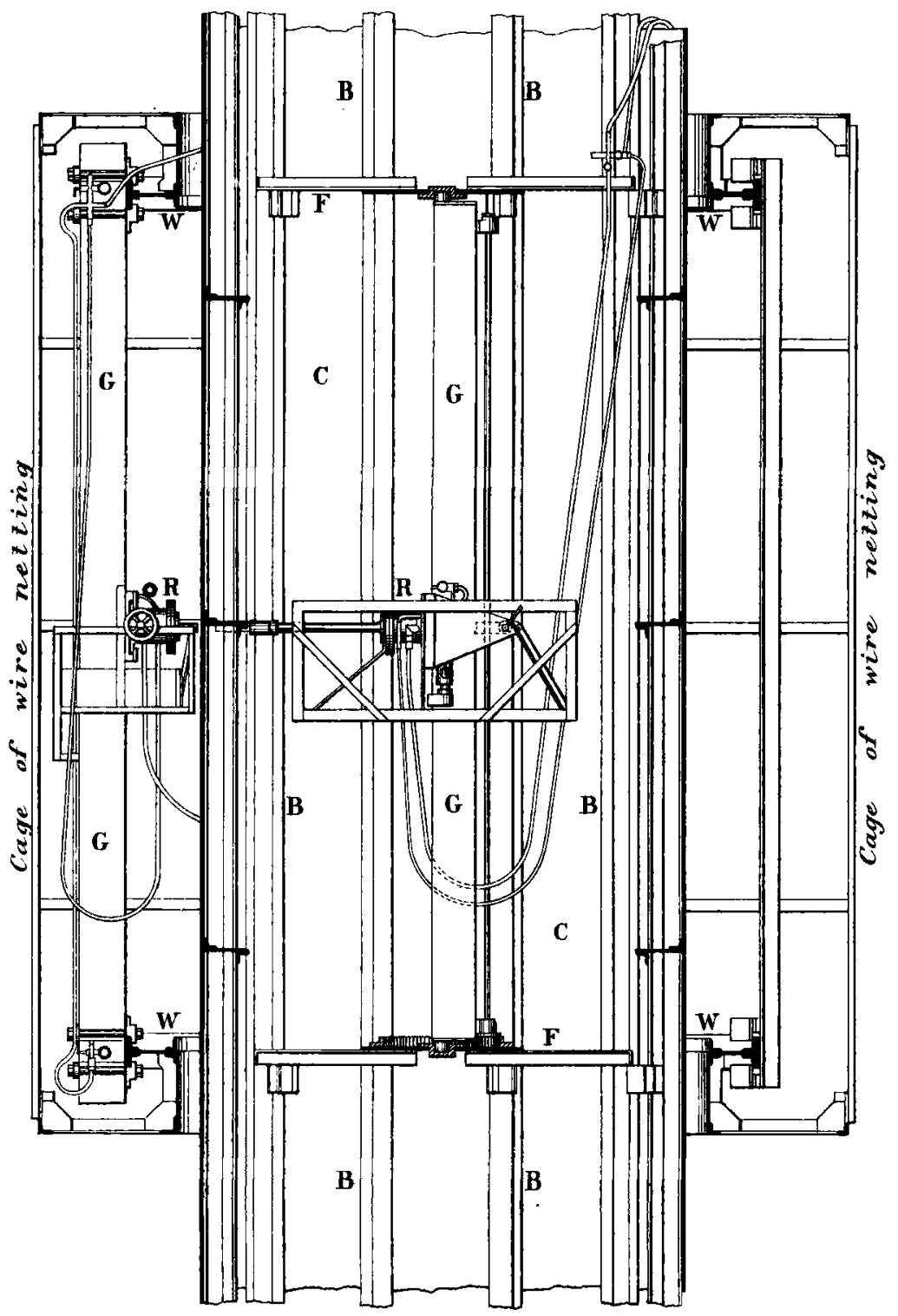

Irs. 0

5

10

15 
FORTH BRIDGE MACHINERY. Plate 55. Riveting Machine for Vertical Columns of Piers.

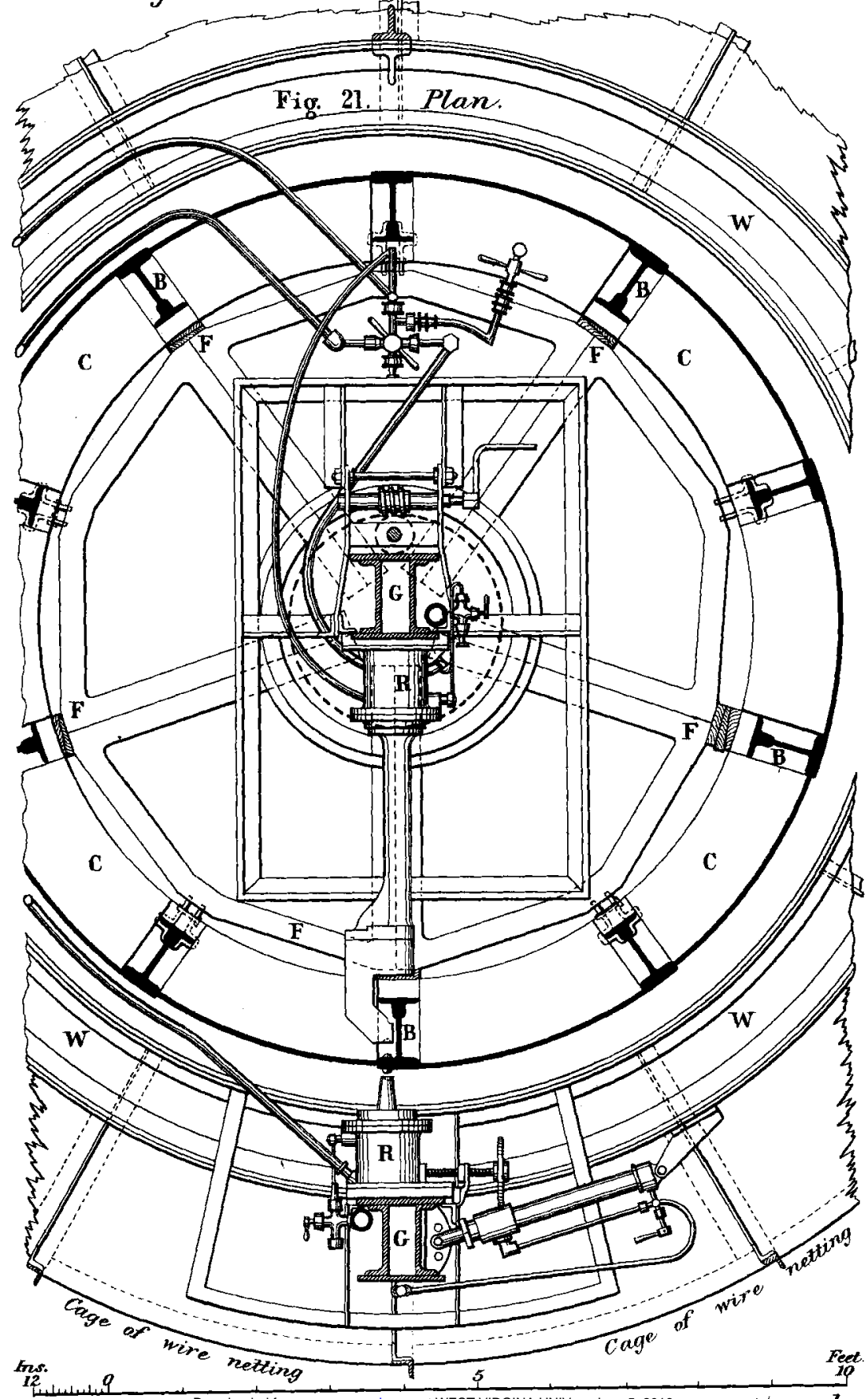

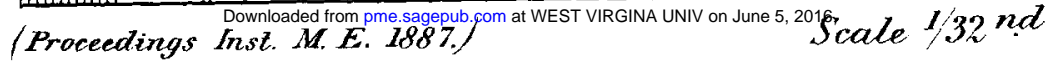

